south of $-30^{\circ}$ declination. With regard to the work at Yale Schlesinger remarked that the zone $+20^{\circ}$ to $+30^{\circ}$ which has just been finished has required many new experiments. It will be possible to finish future zones in about half the time.

The President proposed the nomination of a sub-committee for dealing with the re-observation by means of photography of the A.G. zones and the observations of standard stars for the reduction of the plates.

The sub-committee was constituted as follows:

Schlesinger, chairman; Boss, Jackson, Spencer Jones, Kopff, A. Lambert, Moreau and Morgan, members.

The following recommendation was proposed by Dr A. Lambert and approved by the Commission:

"La Commission prend en considération la proposition de M. Mineur, relative à l'étude des mouvements propres des étoiles éloignées de la galaxie; elle recommande l'observation des étoiles de son programme, programme reproduit succinctement dans le rapport du Président (p. 3I (I) (a)). Elle souhaite pour cet objet une entente entre un certain nombre d'Observatoires, entente qui pourrait être provoquée par le Président de la Commission."

It was stated by M. A. Lambert that a list of about 4000 stars north of $-I 5^{\circ}$ had been prepared. One-third of the list is being observed at the Paris Observatory, another third in Uccle. The co-operation of other observatories is invited.

\title{
Commission 9. (Astronomical Instruments.)
}

Acting President: M. le Comte de la Baume Pluvinel.

Secretary: Prof. H. Chrétien.

The Commission discussed and adopted the President's report and passed the following resolution for submission to the General Assembly:

"La Commission souhaite que l'on se mette d'accord pour définir des nombres caractéristiques pouvant représenter les qualités optiques des grands instruments."

\section{Commission I2. (Solar Physics.)}

President: Dr C. E. St John.

SeCretary: Dr M. Minnaert.

Dr St John explained why it would be necessary to reorganize Section 12 . In the Committee there were too many members and too many sections. It was impossible for the President to write to 70 persons ! At the request of the general secretary, propositions would be made for a fresh arrangement.

A first scheme was drawn up by Dr St John, Prof. Abetti, Prof. Brunner, Dr d'Azambuja and Dr Minnaert, in a preliminary meeting where they discussed the reorganization problem. This scheme was as follows:

A. Solar Eclipses.

B. Solar Physics.

r. Sun-spots, positions and areas.

2. Sun-spot numbers and character figures.

3. Prominences.

4. Spectroheliograph.

5. Solar radiation: ultra-violet and total. 
6. Solar rotation.

7. Problems of the solar atmosphere, theoretical and observational.

8. Spectrohelioscope.

Dr St John explained that the two centres for visual and photographic observation of prominences had been combined into one, that similarly the centres for spectroheliography in $\mathrm{H} \alpha$ and in $\mathrm{K}$ light had been combined, and that the centre for solar rotation had been restored, because the subject was becoming very interesting once more. Centre 7 would be one of the most important ones.

Prof. Stratton emphasized that there was no question of principle involved in the proposed new arrangement, but only a question of organization. The machinery for correspondence and co-option was too complicated for one large Commission: moreover, if someone was interested in one particular line of solar research, he did not know when he had to attend the meetings of the Commission. The following scheme was proposed by Prof. Stratton:
A. Sun-spots.
B. Upper atmosphere.
C. Solar spectroscopy.
D. Solar radiation.
E. Eclipses.

Dr St John explained further how his scheme was conceived. We should have to nominate three persons (including the President) for each centre; these could co-opt as many other persons as they wished. The director of each section was to be responsible for that section, and to correspond with the President of the whole Commission.

Prof. Mitchell suggested the possibility to sub-divide the committees A-E in as many centres as would be useful, by adding numerals.

Dr Lockyer agreed with that proposition.

Father Rodés preferred the first scheme, because if we selected the other, we should be obliged to sub-divide again, and we should not have a suitable organization for many years.

Prof. Dingle would prefer to sub-divide as little as possible. An astronomer interested in $\mathrm{B}_{7}$ would also be interested in B6, and one interested in $\mathrm{B}_{3}$ also in $\mathrm{B}_{4}$. The observation of eclipses would be of importance for different centres.

Dr Minnaert thought that the greater number of sub-divisions in the first scheme was only apparent; the great problems of the solar atmosphere were still preserved as one unity, and the statistical work was relegated to the smaller centres.

Prof. Abetti agreed with that, but suggested that the "section problems of the solar atmosphere" might be called "solar constitution," and work in agreement with Commission 35, on the constitution of the stars.

Prof. Da Costa Lobo thought that the reorganization was simply administrative, and preferred the first scheme.

Dr Lockyer suggested that "upper atmosphere" should be replaced by "prominences and spectroheliograms."

Prof. Plaskett as a chairman of the Committee for Nomination of the members, asked that the sub-divisions should be made as simple as possible and not too numerous.

Dr Menzel thought that with both schemes we should run into difficulties, because a number would belong to more than one group. He preferred the first scheme, but suggested that centres I and 2, 4 and 8 should be combined. 
Father Rodés agreed with that proposition. Moreover he proposed to consider the eclipse sub-division not as a new committee, but as the first centre.

Dr Pettit thought that solar spectroscopy was not sufficiently considered in the group "problems of the solar atmosphere."

Prof. Eddington agreed with Dr Pettit. Centre 7 ought to be called "solar spectroscopy."

Prof. Mitchell amended his proposition and suggested that the number of new committees be 4 , viz.:

Sunspots and character figures.

Chromospheric phenomena.

Solar spectroscopy.

Solar eclipses.

Prof. Stratton agreed with this amendment. He feared that the scheme of Dr St John would not give to the co-opted members their full rights, unless their nomination was made by all the members of the Committee for Solar Physics.

Dr Lockyer also agreed with the amendment.

Dr St John explained that in his idea all the members of the centres of Commission $\mathrm{I} 2$ should be nominated by the whole Commission and have their full rights.

Prof. Carroll would like to see combined the centres 5 and 7 of the first scheme; this was practically done by the second scheme.

Prof. Dingle suggested that the Commission C be called: "Commission for solar radiation." This would include spectroscopy, but there remained also for investigation the light as a whole. In all cases our sub-divisions would be artificial.

M. d'Azambuja preferred the first scheme, because there was more unity, one and the same President.

Prof. Mitchell also agreed with "solar radiation" instead of "solar spectroscopy."

Dr Minnaert asked if it was impossible to give the full rights to the members co-opted, and Prof. Stratton answered that this would be possible if the whole Commission nominated them; this, however, was rather complicated.

Father Rodés asked that a vote should be taken, first about the sub-division, afterwards about the question of nominating the members.

The amended motion of Prof. Mitchell was carried with ten votes for, nine against.

Dr St John then opened the discussion on the reports of the different centres printed in the "Draft Reports."

From Father Rowland at Stonyhurst a report had been received on the work his observatory was doing on sun-spot numbers; the spectrohelioscope was nearly ready.

Dr Pettit had given a complete account of his work in the Astrophysical Journal. Unfortunately, there was no check on the method of eliminating the atmospheric influence. The variations found were still too large to be attributed to anything on the sun we know; in the monthly means for the radiation at $\lambda_{3200}$, the variation amounted to 75 per cent.

Dr St John showed graphs of the solar rotation and its changes since I908. The speed of rotation of the chromosphere is increasing now and will soon be greater than that of the photosphere. Between maximum and minimum, the difference amounted to fully 2 days per revolution.

Prof. Brunner had calculated the correlation between the figures for the terrestrial magnetism and several solar phenomena, as given by the character figures. This correlation is: 


$\begin{array}{clc}\text { For the Ca-flocculi } & 0.86 \pm 0.10 \\ \text { " } & \text { H-flocculi (bright) } & 0.81 \pm 0.13 \\ \text { " spots } & 0.85 \pm 0.1 \mathrm{r} \\ \text { " H-flocculi (dark) } & 0.88 \pm 0.09 \\ \text { " } & \text { limb-prominences } & 0.98 \pm 0.01\end{array}$

This correlation was calculated year to year. Prof. Brunner thought that clearly the main aim of the character figures of the I.A.U. had been reached, i.e. to give quick information about solar activity.

\section{Subventions.}

Dr St John opened the adjourned meeting and explained the lines along which we had to consider the demands for subventions. The I.A.U. as a rule gave only subventions for the co-operation between several stations, not for the work of one particular station. The petitions of Meudon and Arcetri, asking for continuance during the next years of the subventions received in the past years, came under the general rule.

Dr d'Azambuja and Prof. Abetti explained the international importance of the work for which they asked a subvention.

The Commission unanimously expressed the wish that the Executive Committee should grant the subventions for which MM. d'Azambuja and Abetti had asked.

A motion was carried, emphasizing the importance of the work done at the Coimbra Observatory by Prof. Da Costa Lobo.

Father Rodés reported that the Spanish government had cut down the subventions of the Observatory at Tortosa; any grant from the Union would facilitate the continuation of his work.

Prof. Carrasco replied that nevertheless the Government at Madrid was very interested in science and particularly in astronomy; the observatory at Madrid would do what it could in order to continue the international co-operation and to help the observatory of Tortosa.

Dr St John hoped that the Spanish government would consider the great importance of the work of Father Rodés.

Father Rodés added that he would in any case endeavour to find money for his work, even if the Union could not give him a subvention.

Dr St John proposed that the question of the Character Figures should be discussed now.

Prof. Stetson wished that astronomers should realize, that radio was a very good method of investigating the Heaviside layer and thereby the solar activity. There appeared to be a close relation between the intensity of radio reception and solar activity; the correlation was especially strong with the sun-spot numbers. Co-operation with radio workers would furnish a great amount of material, so that we could picture the fluctuations of the height of the Heaviside layer at one determinate point, and the peaks and troughs in that layer. Moreover, Prof. Stetson would suggest that spectrophometric measurements might be made in the solar spectrum, in order to detect possible variations.

Dr d'Azambuja read a communication from Prof. Deslandres on magnetic storms as follows:

Dans cette Note, où je ne prends pas parti et que je résume simplement sans commentaires, M. Deslandres expose les résultats qu'il a obtenus par l'étude de la répartition, dans le temps des orages magnétiques. Elle contient aussi la réponse à 
certaines critiques que divers auteurs, notamment Salet, Chree et Bartels, ont formulé sur ses travaux.

L'examen d'un assez grand nombre d'orages magnétiques et des pointes isolées que présente parfois le courbe de la déclinaison dans les jours calmes, lui a d'abord permis de retrouver la loi de périodicité de 27 jours, énoncée autrefois par Marchand et confirmée par Maunder.

Mais cet examen lui a permis en outre de reconnaître une périodicité plus courte, de 4 jours et demi et même de $I \cdot I$ jours.

Faisant alors l'hypothèse que cette périodicité, à l'arrivée sur la terre, existe, avec la même valeur, au départ du Soleil des particules électrisées qui provoquent les mouvements de l'aiguille aimantée, il en conclut que tout se passe comme si le Soleil possédait, dans le cas de la plus petite périodicité, 24 volcans émettant des particules par intermittence et répartis régulièrement suivant des méridiens espacés de $15^{\circ}$.

Pour voir ces subdivisions de la périodicité de 27 jours, il est nécessaire de séparer les uns des autres les trains d'orages successifs qui, dans les longitudes solaires, sont décalés les uns par rapport aux autres.

Quand on les considère tous ensemble, les subdivisions disparaissent. C'est pourquoi Salet, Chree et Bartels qui ont traité le problème du point de vue statistique, ne les ont pas entrevus et ont mis leur existence en doute.

Prof. Bosler thought that the influence of earth currents on the magnetic field must be carefully considered. The capital question was, whether the varying earth currents were the cause of the magnetic storms, or whether the reverse was true. His work showed that the first hypothesis was really exact. His results were obtained from a study of the magnetic observations at Greenwich and St Maur and from those of the Observatorio del Ebro. We should have to see if the results of the other countries would agree with these.

Dr St John explained that the Committee for Solar Physics had been asked to nominate two members in the Commission for Solar and Terrestrial Relationships, established by the International Council of Scientific Unions: they were at present Dr St John and Prof. Abetti. Prof. Abetti had been elected President of that Committee, so that a place was vacant.

The Committee for Solar Physics recommended that Dr d'Azambuja be elected in Prof. Abetti's place.

Finally, Dr d'Azambuja submitted to the members present a series of spectroheliographic images obtained at the Observatory at Meudon, and asked that the numbers for the intensity of chromospheric phenomena attributed to them should be compared with the scale of other observers.

At a subsequent meeting Prof. Carroll, in the chair, read a communication from Prof. Milne, concerning theoretical problems which must be solved. Consecutively, Dr Minnaert, Dr Richardson, Miss Moore gave a short account of their recent researches on spots, and offered suggestions for further observations. Dr Nicholson discussed the Mt Wilson measurements on the radiation of spots. Dr Pettit remarked that the temperature of the surrounding photosphere must be put equal to $5960^{\circ}$ and not to $5740^{\circ}$, because of the darkening at the sun's limb.

At the request of Prof. Stetson, Dr Minnaert gave a short account concerning the brightness near the extreme limb, as determined from the measurements of Prof. Stetson during the last minutes before totality.

Dr Menzel read a paper, giving different suggestions for observations of the 
chromosphere. In the discussion concerning this paper, Dr d'Azambuja informed the Committee that there were no relations between the ordinary granulation and the "granulations" in the $\mathrm{H} \alpha$ light; the last ones were much bigger, and were due probably to movements in the chromosphere itself. He would attempt to make spectroheliograms in the $S i$ line. Moreover, he thought that the spectroheliographic determination of the diameter of the Sun and of the height of the chromosphere was one of the best methods of determining this height. Prof. Da Costa Lobo emphasized the importance of the very small prominences.

At the request of the President, other new suggestions were made. Prof. Da Costa Lobo had observed variations in the brightness of Baily's beads during eclipse and asked that this phenomenon should be investigated. Prof. Carroll hoped that the conductivity in the solar atmosphere would be investigated, so that it might be possible to account for the magnetic field of the Sun. Moreover he asked that observations be made on the intensities of lines in prominences. Finally he hoped that the work of Lyot would be extended, and that the possibility of getting interference fringes would be considered.

Dr d'Azambuja gave an account on the installation of the spectrohelioscope at Meudon, where it was adapted to the spectroheliograph; it was easily possible to record eruptive phenomena either visually or photographically, with intervals of only one minute.

The following suggestions for solar observations were adopted by the Commission:

Maximum visibility of faculae.

Intensity distribution in the continuous ultra-violet.

Intensity distribution near the extreme limb.

Brightness of sun-spots in different wave-lengths and positions.

Spectrum of faculae.

Contours of Fraunhofer lines, residual and total intensities, variation near the limb.

Polarization of the corona in different wave-lengths.

Transition between thermodynamic and monochromatic equilibrium.

Hydrodynamics of a sun-spot.

Radiation emitted by an ionized column.

Origin and meaning of turbulence.

Complete spectrum of one spot on a large scale.

Differences between the spectra of different spots.

Magnetic field in different spots and different spectral regions.

Spot spectrum in ultra-violet and in infra-red.

Explanation of the strengthening of faint lines in the spot spectrum.

Calibration of the Rowland scale in absolute values.

Profiles of chromospheric lines.

Relation between small chromospheric spikes and faculae.

Changes in the forms of these small spikes.

Forms of prominences in different lines.

Spectroheliograms in the line 3905 of Silicon.

Interferometer wave-lengths of chromospheric lines.

Exact definition of "the height of the chromosphere."

Two eclipse meetings were held with Prof. Stratton in the chair, one to hear an account of the observations of the recent eclipse and one to discuss coming eclipses.

Dr Jackson stated that the Greenwich party had a good equipment at Parent, 
but had got only a few results on account of clouds: Slit spectrograph-no results; Coronagraph-only inner corona; Prismatic camera-good first flash and two coronal rings and prominences. It was intended to test with a red filter and a panchromatic plate whether star images could be found near the limb, but only a corona picture in red light was obtained, without any star images.

Dr Dufay gave an account of the observations at Louiseville. Slit spectrograph for polarization of the corona, 2 prisms, $60 \mathrm{~mm}$. aperture, $200 \mathrm{~mm}$. focal length; birefringent prism and quartz lamina before the slit: the plates seemed to be good.

The spectrum of the sky near the eclipsed Sun was examined: it showed only Fraunhofer lines.

Dr Shane of the Lick Observatory mentioned results obtained at Fryeburg: excellent direct photographs of corona and prominences; flash recorded on moving plate and on motion picture film, in the visual and the photographic region; 5 spectrographs on one axis for corona spectrum; $\lambda 6734$, photographed with third order Rowland grating, was over-exposed; good spectrum of outer corona. Interference fringes of green coronal lines very indistinct.

Dr Witkowski, Poland, stated that a cinematographic record had been secured of the contacts, I300 pictures timed with an accuracy of $\frac{1}{50} \mathrm{sec}$.

Dr Andrews, Harvard, gave an account of the observations at Gray, Maine: six images of the corona in different spectral regions; inner corona photographed with silvered lens; long streamer on the infra-red image. Photoelectric measurement of the brightness of the corona; the determination of the colour by this method would be very difficult; three pinhole cameras were successful. Photographs of the corona with a reflector; Dr Cohn, who joined the Harvard party, investigated the polarization of the corona visually and photographically.

Prof. Hirayama, Japan, stated that good results had been secured at Alfred with the coronagraph and prismatic camera; too short exposures with the grating and the polariscope.

Prof. Donitch had been successful with his coronagraph and prismatic camera and hoped to have good results.

M. le Comte de la Baume Pluvinel reported further on the observations at Louiseville: coronagraph with concave lens, partly spoiled by slight clouds; I-prism spectrograph for the corona; prismatic camera with a quartz-fluorite prism for ultra-violet; with a coronagraph of Lyot's construction, the corona was seen well before totality.

Prof. Stratton congratulated the observers who had been successful.

At the second meeting Mr Weld Arnold described the track of the I934 eclipse and the difficult conditions at Minto Reef, which was only $6 \mathrm{ft}$. above high water and at Losap where a tidal wave had once swept the island, while the fourteen inhabitants had had to climb trees to save their lives; Wake island was 50 miles outside the belt of totality. Capt. Hellweg of the United States Navy expressed a hope that the United States Navy would send an expedition to Pys, an island $300 \times 500$ metres in size. Dr Minnaert suggested that the S.E. coast of Halmaheira might be suitable though the Sun would be low. Mr Robertson mentioned that as seen from Losap the Sun would lie in a good field for the Einstein experiment.

Prof. Gerasimovic described the track of the 1936 eclipse. The altitude of the Sun would be very low in Greece; the Caucasus would not be so favourable as Siberia; the altitude would be $57^{\circ}$ at Krasnoyarsk near Lake Baikal and the duration there would be $\mathrm{I}_{5} \mathrm{I}$ sec.; the meteorological conditions were fair. The Moscow Astronomical Institute was collecting data and would publish a report at 
an early date. In Japan the altitude would be lower again and the duration of totality less.

It was agreed to ask Dr Minnaert, Capt. Hellweg, Prof. S. Hirayama and Mr Eropkin, secretary of the Solar Commission of the Leningrad Academy of Science, to act as advisers to be consulted by would-be observers and to arrange co-operation.

Outstanding eclipse programmes were then discussed and the following suggestions were made for observers' programmes:

(a) Accurate wave-length determination with high dispersion spectrographs, at the cusps for different levels in the solar atmosphere, with a study of changes at different levels.

(b) More accurate coronal wave-lengths.

(c) Work in the extreme infra-red and ultra-violet both for the corona and the chromosphere.

(d) Coronal photography.

(e) Photometry of corona.

$(f)$ Polarization of inner and outer corona and a study of the law governing the variation with distance from the limb.

(g) Distribution of coronal motions by an objective interferometer.

(h) Widths of chromospheric lines, in profile, especially at high levels.

(i) Changes of colour of skylight at eclipse.

(j) Contours and displacements of absorption lines in the outer corona.

(k) Duration of Baily's beads.

(l) Photometry of the vanishing crescent.

$(m)$ Photography of Mercury at eclipse, when placed at a high altitude.

$\mathrm{Mr}$ Robertson offered to arrange for the computation of the tracks of further eclipses and mentioned that the track of the I937 eclipse-a seven-minute eclipsenowhere touched land. An island, which had once lain in the track, had sunk below the ocean. He was asked to compute the track of the r 940 eclipse so that meteorological observations might be made along the track.

\section{Commission I4. (WAVE-LeNGTHS.)}

Acting President: Mr H. D. Babcock.

Secretary: Mr W. F. Meggers.

A provisional list of recommendations based upon the Draft Report prepared by Prof. Fowler served as a guide for discussion and action by the committee. The recommendations, together with a digest of the discussion and the action taken, are reported below as a record of the proceedings of Commission I4.

I. It is recommended that two or more observers should investigate the possibility of simplifying the specification for the production of the primary standard by using a source that will give well-defined fringes with retardations greater than 200,000 wave-lengths. No action taken.

The discussion was opened by Mr Meggers, whose remarks are summarized as follows: In the Draft Report of I928 (p. 84) recommendation No. I proposed " that the Union modify the provisional specifications adopted in I 925 for the production of the primary standard of wave-length so as to agree with those adopted in 1927 